\section{Práticas e mecanismos de uma tecnologia social: proposição de um modelo a partir de uma experiência no semiárido}

\author{
Practices and mechanisms of social technology: a model proposition from \\ an experience in the semi-arid region of Ceará
}

Ana Clara Aparecida Alves de Souza ${ }^{a}$

Marlei Pozzebon ${ }^{\text {bc }}$

a Pontifícia Universidade Católica do Rio Grande do Sul, Porto Alegre, RS, Brasil

- HEC Montréal, Montreal, Canadá

• Fundação Getúlio Vargas, São Paulo, SP, Brasil
Revista Organizações \& Sociedade 2020, 27(93), 231-254

(C) Autor(es) 2020

DOI 10.1590/1984-9270934

ISSN 1984-9230

www.revistaoes.ufba.br

NPGA, Escola de Administração

Universidade Federal da Bahia

Recebido: 01/12/2017

Aprovado: 23/07/2019

\title{
Resumo
}

As crescentes desigualdades sociais, que desencadeiam e acentuam a exclusão social e a pobreza, têm reforçado a relevância da inovação social para a formulação de respostas alternativas ao que tem sido oferecido em modelos consolidados pelo status quo. Esta pesquisa considera a inovação social através da lente da tecnologia social, um conceito desenvolvido e documentado por pesquisadores latinoamericanos. Considerando a relevância das tecnologias sociais para a transformação de cenários sociais desfavorecidos, este estudo busca oferecer uma contribuição central: a concepção de um modelo conceitual, de natureza processual, que permite a identificação de mecanismos-chave subjacentes à transformação promovida por uma tecnologia social. Os resultados foram produzidos a partir de um estudo de caso único e em profundidade de uma organização da sociedade civil de interesse público que atua no semiárido cearense e vem promovendo transformações sociais na região, sobretudo contribuindo para a redução do êxodo de jovens por meio do fomento ao empreendedorismo rural. Como resultado do estudo, operacionalizamos um modelo conceitual para teorizar tecnologias sociais que contribui para uma melhor compreensão de seus mecanismos de funcionamento e modos de ação.

Palavras-chave: Tecnologia Social; Inovação Social; Transformação Social; Semiárido Brasileiro.

\section{Abstract}

Growing social inequalities, which trigger and accentuate social exclusion and poverty, have reinforced the relevance of social innovation to formulate alternative responses to what has been offered in models consolidated by the status quo. This study analyzes social innovation through the lens of social technology, a concept developed and documented by Latin American researchers. Considering the relevance of social technologies for the transformation of disadvantaged social scenarios, this study offers a central contribution: a conceptual model of processual nature that allows for the identification of key mechanisms underlying the transformation promoted by a social technology. The results were produced from a single, in-depth case study of a civil society organization of public interest that has been promoting social transformations in the semi-arid region of Ceará, mainly contributing to reduce the exodus of young people by the promotion of rural entrepreneurship. As a result of this analysis, we developed a conceptual model to theorize social technologies that can contribute to the better understanding of their mechanisms and action model.

Keywords: Social Technology; Social Innovation; Social Transformation; Brazilian Semiarid Region of Ceará. 


\section{Introdução}

A importância que a inovação social ocupa nos dias atuais tem sido globalmente reconhecida. Nos tempos turbulentos experimentados na segunda década do século XXI, marcados por crescentes desigualdades sociais, buscam-se novas formas organizacionais e associativas que procuram combater a exclusão social e a pobreza. Entre os resultados negativos da globalização está o aumento de distorções e de desigualdades em todos os recantos do planeta, impondo condições que aceleram a complexidade da vida social (Mendell, 2016).

Processos de inovação social emergem e se desenvolvem pela participação e engajamento dos atores sociais na transformação das relações e interações sociais. Trata-se de um processo de construção social e da geração de soluções dependentes de trajetórias historicamente situadas (Thomas, 2009). Entre os maiores desafios enfrentados pelos gestores e promotores de programas de inovação social, dois alcançam grande destaque: a sustentabilidade ou perenidade, no longo prazo, dos programas implantados, e a transferibilidade ou reaplicação desses programas entre diferentes contextos (Moulaert, MacCallum, Mehmood, \& Hamdouch, 2013). Muitos pesquisadores, tanto na esfera internacional quanto na brasileira, têm se debruçado sobre esses dois desafios. No entanto, diversas lacunas ainda precisam ser exploradas, empírica e teoricamente (Bitencourt, Marconatto, Cruz, \& Raufflet, 2016; Duque \& Valadão, 2017).

Nosso trabalho visa contribuir para a compreensão dessas lacunas e, para isso, desenvolvemos nosso argumento em dois passos. O primeiro visa compreender programas de inovação social através da lente teórica das tecnologias sociais e busca um maior grau de teorização sobre ela. O segundo está ancorado na premissa de que, tanto para a perenidade quanto para a transferibilidade de uma tecnologia social de um contexto para outro, devemos antes compreender os caminhos que levam à transformação social no contexto de origem. Nesse sentido, formulamos a seguinte questão de pesquisa: quais são os mecanismos-chave colocados em prática por uma tecnologia social que ajudam a promover as transformações sociais desejadas localmente? A partir das reflexões encaminhadas por esse questionamento, apresentamos um modelo conceitual para teorizar tecnologias sociais.

Adotamos o referencial teórico de tecnologias sociais desenvolvido e documentado por teóricos latino-americanos (Dagnino, 2009), por entender que ele oferece uma lente coerente com a nossa postura crítico-construtivista, uma vez que combina construtivismo social com uma visão crítica e política das inovações sociais. Thomas (2009) define tecnologias sociais como formas de criar, desenvolver, implementar e administrar tecnologias orientadas a resolver problemas sociais e ambientais que geram dinâmicas sociais e econômicas de inclusão social e de desenvolvimento sustentável. Tecnologia é definida aqui em sentido amplo, incluindo ferramentas, métodos e arranjos organizacionais.

As tecnologias sociais são concebidas e implementadas para promover transformações a partir da interação e da luta política entre diferentes grupos e procuram defender interesses e necessidades das comunidades locais, desenvolvendo uma crítica ao status quo e reivindicando mudanças profundas (Dagnino, 2009). O conceito de tecnologia social emergiu ao longo dos anos 1990 como tendo o potencial de contribuir para a consolidação de práticas democráticas concebidas e fundadas pela geração coletiva de ideias.

Duque e Valadão (2017) analisaram a evolução do conceito através da revisão de toda a produção brasileira entre 2002 e 2015 e chegaram a duas visões principais: tecnologia como práticas sociais, que proporcionam transformações sociais em uma e por uma comunidade (construção social, adequação sociotécnica), e tecnologias como artefatos geradores de mudanças sociais (tecnologias para o social).

Vale ressaltar que as influências teóricas que permeiam a construção do conceito de tecnologia social combinam a construção social da tecnologia com uma teoria crítica da tecnologia, como proposto por Feenberg (2002), que mobilizou algumas ideias marxistas e enfatizou a presença do poder tecnocrático, em que especialistas e decisões políticas de controle de natureza técnica são baseados em interesse pelo controle e pelo poder. Essa trajetória ajuda na compreensão de por que chegamos à definição de 
tecnologia social como o resultado de processos políticos - processos de reconfiguração ou imbricação sociotécnica - que criam espaços e ocasiões para redefinir os acordos entre grupos sociais, os artefatos e os métodos que eles mobilizam na vida cotidiana, especialmente para a produção e o consumo.

No centro dos processos políticos que resultam em tecnologias sociais estão as práticas sociais, que envolvem métodos e ferramentas e são desenvolvidas e mobilizadas por diferentes grupos sociais. Esses grupos são, sobretudo, locais e agentes primeiros do processo. Nosso argumento central é que somente identificar as práticas sociais não é suficiente. É importante identificar o que acontece uma vez que essas práticas são operacionalizadas em dado contexto. Chamamos esses elementos de mecanismos-chave, ou seja, processos que são alavancados pelas práticas e que permitem que transformações sociais aconteçam.

Para explorar nossa questão de pesquisa, investigamos uma tecnologia social que vem promovendo transformações sociais na região do semiárido do estado do Ceará. Trata-se do Programa Jovem Empreendedor Rural (Pjer), desenvolvido pela Agência de Desenvolvimento Econômico Local (Adel), uma organização da sociedade civil de interesse público (Oscip) criada por jovens cearenses em uma região semiárida no Ceará e que, após alguns anos de atividade, passou a ter seus programas de inovação social replicados no nordeste do Brasil. A Adel trabalha com a profissionalização das atividades desempenhadas por agricultores familiares e com a capacitação de jovens para o desenvolvimento de negócios rurais que Ihes permitam permanecer em suas comunidades, contribuindo para o desenvolvimento econômico local e para a redução dos índices de migração (êxodo rural). Seus resultados positivos continuam crescendo desde a sua criação, em 2007.

Ao adotar a lente das tecnologias sociais como uma alternativa teórica para o entendimento dos programas de inovação social, nosso estudo oferece um modelo conceitual de natureza processual, que contribui para a identificação dos mecanismos-chave que ajudam a compreender como mudanças sociais desejadas podem ser alcançadas. Muitos são os artigos que analisam aplicações e problemas ligados à concepção e implantação de tecnologias sociais, conforme apresentaremos por meio da revisão da literatura. Encorajadas por uma recente revisão bibliográfica da produção brasileira sobre inovação social e tecnologia social, compreendida entre os anos de 2007 a 2018, que destaca a relevância de uma consolidação da compreensão teórica do tema, nosso trabalho busca dar um passo na direção de operacionalizar um modelo conceitual para teorizar tecnologias sociais e contribuir para uma melhor compreensão de seus mecanismos de funcionamento.

\section{Referencial teórico}

$\mathrm{Na}$ introdução a uma edição especial sobre inovação social, Bitencourt et al. (2016) argumentam que problemas sociais representam tanto oportunidades quanto desafios para as organizações. Os autores apontam a relevância da pesquisa em inovação social considerando que, embora esse tipo de inovação exista há muito tempo no campo da prática, falta ao tema um maior desenvolvimento dos aspectos teóricos. 0 termo de base - inovação - tem sua origem em trabalhos europeus e norte-americanos que tratam do tema de forma mais abrangente e, progressivamente, foi incorporado ao vocabulário dos pesquisadores, profissionais e ativistas dedicados a compreender transformações sociais.

São duas as principais vertentes teóricas internacionais da inovação social. Uma é a abordagem "neoshumpeteriana", prevalecente na literatura inglesa, que compreende a inovação social como uma nova ideia ou uma nova combinação de ideias existentes que atende a uma necessidade social, visando dar respostas a problemas sociais. Essa é uma visão mais instrumental e funcionalista do fenômeno. A segunda vertente, de origem francófona, denominada "institucional", compreende a inovação social em uma leitura de mais longo prazo, promovendo mudanças em paradigmas mentais e em quadros cognitivos de uma sociedade. No entanto, nem todos os pesquisadores que se interessam pelo tema da transformação social utilizam o termo inovação social como conceito-chave (Andion, Ronconi, Moraes, Gonsalves, \& Serafim, 2017), podendo ser o termo "tecnologia social" uma alternativa de acordo com o contexto e a discussão pretendida. 
Apesar da relevância da profícua literatura internacional sobre o tema da inovação social, neste artigo destacamos parte da produção brasileira mais recente sobre o tema e, particularmente, os trabalhos desenvolvidos em torno do conceito de tecnologia social. Em maio de 2018, realizamos uma busca no sistema de indexação Scientific Periodicals Electronic Library (Spell). A busca pelos termos "inovação social" e "tecnologia social" resultou em cerca de 45 publicações, que vão de 2007 a 2018. Organizamos esses artigos por temas, apresentados no Apêndice. Essa revisão da literatura nacional indica que os temas "inovação social" e "tecnologia social" têm gerado um interesse crescente entre os pesquisadores brasileiros, abrindo possibilidades de uma exploração ainda mais profunda do fenômeno. Nesse sentido, tratando especificamente do termo "tecnologia social", em um esforço complementar aos resultados encontrados no Spell, realizamos uma busca no Catálogo de Teses e Dissertações da Coordenação de Aperfeiçoamento de Pessoal de Ensino Superior em maio de 2018 e encontramos 15 dissertações de mestrado e 5 teses de doutorado que trazem o termo central "tecnologia social" em seu título, publicadas no período de 2009 a 2017, na área do conhecimento de ciências sociais aplicadas.

Pode-se afirmar que, na América do Sul, o termo "tecnologia social" pode ser considerado equivalente ao termo "inovação social", carregando uma longa história e um significado epistêmico muito forte. É importante ressaltar, no entanto, que o termo "social technology", utilizado em publicações de língua inglesa, tem um sentido diferente do sentido utilizado na América do Sul, fazendo referência às redes sociais de internet, como Facebook e outras. Apenas quatro artigos publicados em inglês são fiéis à tradição sul-americana e fazem referência às tecnologias sociais enquanto inovação sociais do tipo grassroots (e.g., Miranda, Lopez, \& Soares, 2011; Smith, Fressoli, Abrol, Arond, \& Ely, 2017; Smith, Fressoli, \& Thomas, 2014). Consideramos que a visão sulamericana tem potencial de contribuir e dialogar com as tradições europeia e norte-americana na área, mas que avanços teóricos são importantes para alavancar esse diálogo. Dessa forma, apresentamos a "biografia" do conceito de tecnologia social e o nosso modelo conceitual, desenvolvido para contribuir com o processo de teorização do tema.

Um pouco de história: a construção do conceito de tecnologia social

Com base em uma leitura atentiva de artigos e textos enfocando tecnologias sociais, definimos tecnologia social como o resultado de um processo político de reconfiguração sociotécnica, através do qual práticas sociais mobilizam métodos e ferramentas desenvolvidas com o objetivo de promover transformações sociais que ajudam a resolver problemas e atender necessidades relacionadas à exclusão e à pobreza. Para a compreensão de como chegamos a essa formulação, gostaríamos de resgatar um pouco da história da construção desse conceito.

A compreensão da construção do conceito de tecnologia social, tal como formulado pelos pesquisadores sul-americanos, requer a compreensão do contexto no qual foi criado, contexto esse marcado por desigualdades estruturais produzidas por fatores locais e globais. Ainda nos dias atuais, parte da população sul-americana enfrenta problemas relacionados às precárias condições sanitárias, ao abastecimento de água e energia e ao precário acesso à alimentação, educação, saúde e moradia. Grande parte da população vive em condições de exclusão, e uma das causas desse processo de exclusão social está na própria natureza das tecnologias ditas "convencionais" (Neder \& Thomas, 2010).

Tecnologia convencional é um termo genérico aplicado para designar tecnologias de larga escala que são intensivas em capital, conhecimento técnico e recursos que, muito frequentemente, implicam a exclusão ou empobrecimento do trabalho humano, especialmente na agricultura e em outros diversos setores manufatureiros. Um exemplo claro de tecnologia convencional pode ser ilustrado através da "modernização" da agricultura a partir dos anos 1940, que passa a impor a monocultura extensiva baseada em máquinas agrícolas, produção de sementes híbridas, fertilizantes sintéticos e pesticidas. Ironicamente conhecida como "revolução verde", essa "modernização" da agricultura necessita de altos investimentos em capital e reduz significativamente o número 
de trabalhadores rurais envolvidos. As tecnologias convencionais, desenvolvidas em um contexto ocidental muito específico (contexto dos países industrializados europeus e norte-americanos), quando "transferidas" para países em desenvolvimento, contribuíram, direta e indiretamente, para o processo massivo de empobrecimento do trabalho e exclusão social (Garcia, 2014; Neder \& Thomas, 2010). Todo esse quadro tem convidado a uma reflexão profunda sobre as consequências do processo histórico ocidental de desenvolvimento tecnológico e sobre a necessidade de desenvolver tecnologias de forma diferente, de maneira mais harmoniosa com cada cultura, cada contexto natural e as respectivas necessidades sociais.

O termo tecnologia social é resultado de um longo processo de ressignificações que teve como origem um conceito mais antigo, o de "tecnologia apropriada", cujas raízes são atribuídas ao movimento social iniciado por Mahatma Gandhi, em 1930, contra o domínio britânico (Dagnino, 2009). Já naquela época, Gandhi sonhava com um mundo sem tecnologias de larga escala, estimulando a importância de preservar técnicas artesanais e culturais para melhorá-las, adaptando o atual processo moderno de tecnologia para as realidades ambientais e sociais da Índia (Albuquerque, 2009). A roca de fiar tornou-se um símbolo de unidade nacional e resistência conta a dominação inglesa (Neder \& Thomas, 2010). Embora Gandhi não tenha aplicado os termos "apropriada" e "social" para a tecnologia, ele definiu as linhas básicas para a emergência desses conceitos (Herrera, 1983).

A partir da década de 1960, assistimos à emergência de várias perspectivas que procuravam discutir criticamente o papel da tecnologia na sociedade, com a proliferação de diferentes concepções de tecnologia: apropriada, intermediária, democrática e alternativa, entre outras (Thomas, 2009). Todas estas concepções podem ser consideradas como predecessoras do conceito de tecnologia social e têm em comum o objetivo explícito de contestar os caminhos propostos pelas tecnologias convencionais e responder à problemática do desenvolvimento comunitário, da geração de serviços e de alternativas tecnoprodutivas em cenários socioeconômicos de pobreza e de exclusão. Na história do desenvolvimento do conceito de tecnologia social, Thomas (2009) destaca a concepção de tecnologias democráticas proposta por Lewis Mumford em 1964. 0 avanço da democracia política teria sido obstruído pela supremacia de tecnologias de grande escala, pautadas em direções centralizadoras e autoritárias. 0 autor ressalta que o seu objetivo era alertar aqueles preocupados com a manutenção de instituições democráticas sobre a necessidade de incluir a tecnologia em seus esforços.

Na década de 1970, observou-se a emergência de diversas abordagens que descreviam tecnologias "adequadas" ou "apropriadas" (Jecquier, 1976; Kohr, 1981). Tais abordagens enfatizavam a necessidade de produção da tecnologia em baixas escalas (familiares ou comunitárias), com baixa complexidade, conhecimento científico e tecnológico acessível, baixo consumo de energia e trabalho humano intensivo (Thomas, 2009). Em 1973, o economista alemão Ernst Friedrich Schumacher escreveu Small is beautiful, aumentando a popularidade do termo no contexto europeu (Schumacher, 1973). Na década de 1980, outros termos alternativos foram propostos, mas aceitando a produção em larga escala para acelerar o desenvolvimento econômico (Riskin, 1983). Esses termos focaram em eficiência e tiveram um alcance mais amplo, tendo como alvo tantos países desenvolvidos quanto países em desenvolvimento, comunidades e empresas multinacionais (Jecquier, 1976).

Embora a visão de superar a exclusão social tenha estado presente em toda a trajetória histórica das tecnologias apropriadas, elas não ficaram isentas de severas críticas. Primeiro, elas foram vistas como reprodutoras de padrões paternalistas orientados para a solução de problemas pontuais, muitas vezes construídas sem a confiança local e sustentabilidade em longo prazo (Thomas, 2009). Segundo, com frequência elas adotaram premissas de neutralidade da ciência e visões deterministas da tecnologia como um meio de mudança social, bem como visões românticas e utopistas de tecnologias "neutras" (Dickson, 1974). Algumas falhas nos modelos de tecnologias apropriadas começaram a se tornar mais evidentes: concepção exógena, falta de flexibilidade, austeridade, inadequação aos contextos locais (Thomas, 2009); classificada também como unidimensional, imponente, inautêntica e pseudoprogressista (Duque \& Valadão, 2017). Finalmente, as tecnologias apropriadas também foram percebidas como um simples "downgrade" de tecnologias convencionais reforçando, em última instância, as disparidades 
sociais e estruturas dominantes injustas do terceiro mundo (Dagnino, 2009). A proposta das tecnologias apropriadas resultou na abertura de um processo de reflexão crítica sobre a seleção de tecnologias e o foco na comunidade de usuários. Significou também um aporte-chave para o desenvolvimento do conceito de tecnologia social.

Para ilustrar concretamente as tecnologias sociais usando o campo da agricultura, apresentamos a tecnologia social conhecida como PAIS (produção agroecológica integrada e sustentável), uma forma de produção agrícola que não exige mais do que cinco hectares e que utiliza círculos concêntricos de legumes e outros produtos agrícolas que coexistem com pequenos animais, como galinhas, de forma orgânica e sustentável. Estas pequenas propriedades permitem a uma família de cinco pessoas não somente ser autossuficiente em alimentação básica, mas também vender o excedente, empoderando-a.

O empoderamento destaca-se como fator central aos atores nas tecnologias sociais, além da possibilidade de inovação em contextos escassos de suporte social, fundamental para a resolução de problemas (Feenberg, 2002). Conforme Andersen, Delica e Frandsen (2013), o conceito de empoderamento foi trazido à tona na década de 1970, por Paulo Freire, no livro Pedagogia do Oprimido, e segue como mote essencial de incentivo às potencialidades dos atores sociais. Para Barretto e Piazzalunga (2012), pensar as tecnologias sociais implica uma abordagem científica e tecnológica bastante inovadora, pois insere a comunidade como parte ativa do processo, deixando de ser apenas beneficiária. A apropriação, o uso e a reaplicação do conhecimento, como destacam Rodrigues e Barbieri (2008), são elementos destinados à população e aos autores envolvidos no processo de uma tecnologia social, pois promovem a coerência com um processo democrático de tomada de decisão e contribuem para a eliminação da possibilidade de apropriação privada do conhecimento, devido ao fato de que a novidade apresentada se torna conhecida e de domínio público, condição essencial à sua reaplicação. Bradach (2003) afirma que quanto mais complexa for a teoria de mudança proposta por uma organização, mais complexa será a reaplicação de suas ações, daí a importância da especificação dada pelos seus líderes sobre os elementos que criam valor para o programa e da definição dos principais elementos capazes de reproduzir o valor desejado.

Considerando essa perspectiva de construção do conceito de tecnologia social e refletindo a seu respeito a partir de uma iniciativa emergente no semiárido cearense, argumentamos que a identificação de mecanismos-chave, conforme ilustrado na Figura 1, permite uma compreensão mais profunda do modo de ação de uma tecnologia social.

TECNOLOGIA SOCIAL como um processo

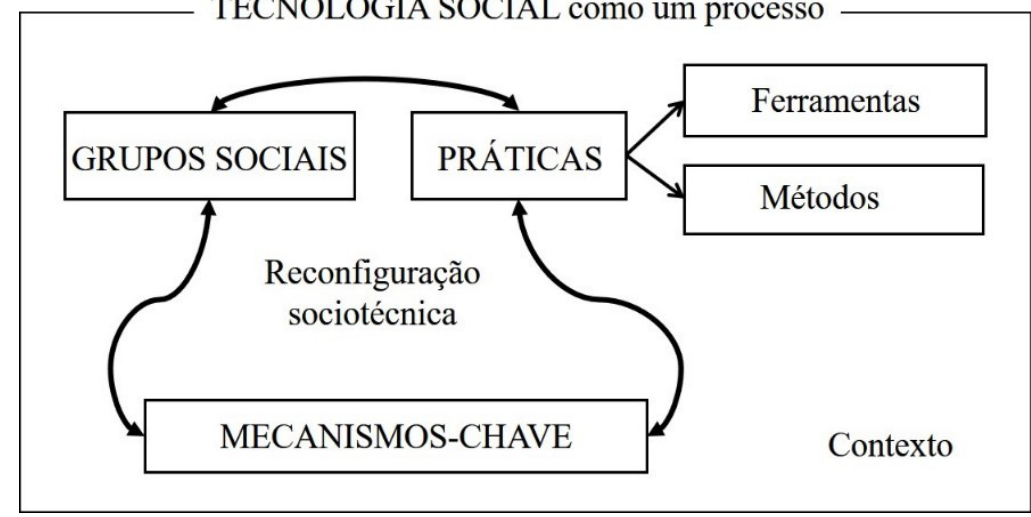

Figura 1 - Modelo conceitual - práticas e mecanismos-chave de uma tecnologia social

Fonte: Elaborada pelas autoras.

Conforme destacamos nos procedimentos metodológicos, os elementos componentes do modelo proposto têm como base a noção latino-americana de tecnologia social na sua proposição fundamental e foram corroborados e enriquecidos a partir da análise indutiva dos dados oriundos do caso apresentado. As setas 
utilizadas entre os quadros sinalizam a interação entre os elementos identificados pela análise e buscam transmitir uma noção de movimento na reconfiguração sociotécnica que se apresenta. 0 elemento "práticas" tem como subelementos identificados "ferramentas" e "métodos". Essa composição de elementos, no contexto estudado, configura, de acordo com o sinalizado pelo modelo, um espaço no qual a tecnologia social ocorre como um processo.

\section{Postura epistemológica e desenho metodológico}

Adotamos, para esta investigação, uma postura crítico-interpretativista, por compreender que abordagens construtivistas objetivam produzir investigações em profundidade sobre a maneira pela qual determinada realidade social tem sido construída, enquanto abordagens críticas se concentram mais explicitamente na dinâmica do poder e da ideologia que cercam as práticas sociais (Alvesson \& Sköldberg, 2000). A fronteira entre uma abordagem construtivista e uma abordagem crítica pode ser vista como uma questão de grau. Alguns estudos alinhados à primeira são sensíveis às relações de poder, enquanto estudos alinhados à segunda incluem uma preocupação em relação aos processos de construção social que sustentam os fenômenos de interesse.

Para explorar nossa questão de pesquisa, optamos por um estudo de caso único e em profundidade. Usando a terminologia proposta por Stake (2005), um estudo de caso é instrumental quando visa produzir resultados que vão além do caso examinado, facilitando a compreensão de uma questão teórica mais ampla através da investigação de um caso empírico particular. O objetivo é produzir um entendimento que poderá ser aplicado não somente ao caso investigado, mas também a outros casos com contextos similares. Trata-se de uma lógica distinta da adotada por autores positivistas, como Eisenhardt e Yin, que tendem a desencorajar casos únicos porque os consideram menos aptos à replicação da unidade de análise e, em consequência, a uma generalização similar à validade externa.

Sob a ótica construtivista, um caso instrumental visa um certo grau de generalização teórica ou naturalística. Estudos de caso construtivistas permitem uma transferência de conhecimento em que ambos, pesquisador e leitor, mobilizam as suas estruturas conceituais e produzem um entendimento teórico do caso estudado. A generalização naturalística é um processo construído tanto pelo pesquisador quanto pelo leitor (Stake, 2005).

O estudo de caso selecionado para esta pesquisa tem como foco o Pjer, desenvolvido pela Adel. Consideramos que o caso Pjer/Adel ilustra as questões problematizadas por nosso estudo, uma vez que a metodologia colocada em prática pelo Pjer é vista pelos seus protagonistas - tanto os membros da Adel como os beneficiários - como uma tecnologia social. As particularidades do caso serão delineadas na seção de análise dos resultados. A condução do estudo de caso realizado está alinhada ao construtivismo, ou seja, busca produzir uma análise detalhada sobre a forma pela qual determinada realidade social tem sido construída, a partir da fala dos seus protagonistas. Buscamos identificar a complexidade das vivências, relações e pontos de vista que indivíduos têm em relação aos espaços nos quais habitam e trabalham e confiar o máximo possível nas visões que os participantes têm da situação estudada pelo pesquisador (Creswell, 2010).

A coleta de dados foi organizada de acordo com o princípio da triangulação de diferentes materiais empíricos: notas da observação no campo, documentos e transcrições de entrevistas. A triangulação, sob uma perspectiva construtivista, tem como objetivo não a "validade" dos resultados, mas o enriquecimento do entendimento dos casos investigados (Stake, 2005). Entre os anos de 2012 e 2014, ambas as autoras conheceram e visitaram a sede da Adel em Pentecoste. Nessas visitas, interagiram com os principais membros da organização, bem como com as famílias e jovens beneficiados pelo programa, observaram, discutiram e refletiram juntamente com os atores "investigados". No sentido de atualizar e complementar as informações apresentadas nesta pesquisa, documentos recentes, disponíveis na web e disponibilizados pela entidade, como a Avaliação de Impacto do Pjer 2016-2017 e o Relatório Anual da Adel (Adel, 2017), foram coletados e integrados à massa de dados. 
Também foram realizadas oito entrevistas semiestruturadas e em profundidade, com duração média de meia hora, elaboradas com base em Glesne (1999). As entrevistas foram registradas entre os meses de novembro de 2013 a fevereiro de 2014, nas cidades de Pentecoste e Fortaleza (na capital foram realizadas duas entrevistas, pois os respondentes estavam nessa cidade na ocasião), no Ceará. O roteiro de entrevistas centrou-se em aspectos contextuais da Adel, transformações, processos, relações entre os atores e inovações locais percebidas pela equipe e pelos beneficiários. Nesse sentido, as experiências e vivências relatadas pelos entrevistados compõem uma parte importante do material empírico necessário à nossa investigação. Cinco entrevistas foram feitas com membros integrantes da Adel; seus respectivos cargos à época das entrevistas eram: primeiro presidente da Adel (entrevista realizada em Fortaleza), diretor-executivo, diretora de comunicação (entrevista realizada em Fortaleza) e dois diretores de projetos. As outras três entrevistas foram realizadas com beneficiários dos programas desenvolvidos pela Adel - um agricultor familiar e dois jovens empreendedores rurais. Outros beneficiários foram convidados pela Adel para conceder a entrevista para a pesquisa, mas apenas os três aqui apresentados estavam disponíveis.

Na coleta, por meio da interação com os entrevistados e das entrevistas semiestruturadas, buscou-se, de maneira indutiva, verificar a emergência de padrões, que nos levaram à identificação dos mecanismos-chave que fazem parte dos resultados. À medida que os atores entrevistados discorriam sobre a constituição da Adel e sua representatividade para aquele contexto, bem como sobre as experiências pessoais e a interferência da Adel em suas vidas, foi possível mapear nas falas, com uso de recursos do software Nvivo 10, elementos recorrentes que nos encaminharam para a identificação dos mecanismos-chave da tecnologia social aqui destacada.

A análise do material empírico foi guiada pelo modelo conceitual (conforme orientação de Miles \& Huberman, 2004), ou seja, procuramos identificar as práticas que constituem o ciclo de trabalho no caso estudado, os grupos sociais envolvidos, as ferramentas e os métodos que caracterizam a tecnologia social em investigação e, finalmente, os mecanismos-chave. Trechos de cada entrevista, observação ou documento foram selecionados e relacionados em nós (códigos, temas) no software Nvivo, à medida que eram identificados como elementos conceituais - grupos sociais, ferramentas, métodos e práticas. Esses elementos nos auxiliaram a categorizar, por meio de uma análise indutiva, os mecanismos-chave que caracterizam as transformações sociais em desenvolvimento. Nas próximas seções apresentamos uma descrição detalhada do contexto do estudo de caso e os principais resultados alcançados.

\section{Adel, uma agência criada por jovens para transformar a vida de outros jovens}

A Adel é uma Oscip que atua beneficiando agricultores familiares e jovens rurais com potencial empreendedor na região semiárida do estado do Ceará, Nordeste do Brasil. Ela foi criada no ano de 2007 por um grupo de jovens da região de Pentecoste (CE) que tiveram a oportunidade de ingressar na universidade e, depois de formados, decidiram retornar às suas comunidades e socializar o conhecimento adquirido, com o objetivo de contribuir para o desenvolvimento local e promover, para os habitantes da região, meios de permanência e convivência no semiárido. Como destaca Santos (2006), podemos ter uma variável global e distante com uma ação local. Um evento pode se dar em um lugar e o seu motor, sua causa última, estar em outro lugar. Assim, a realidade local pode ser percebida considerando a influência global que demanda novas configurações.

A cidade de Pentecoste, onde o projeto teve origem, está localizada a cerca de $80 \mathrm{~km}$ da capital, Fortaleza, conforme ilustrado na Figura 2. O semiárido brasileiro tem como características um clima com temperaturas médias anuais entre $26^{\circ} \mathrm{C}$ e $28^{\circ} \mathrm{C}$, insolação superior a 3.000 horas/ano, além de solos com baixa profundidade (Ribeiro \& Silva, 2010). Tanto o contexto geográfico quanto social do semiárido nordestino evidenciam o imenso desafio dos protagonistas da Adel para enfrentar essas questões e estimular o desenvolvimento local. 


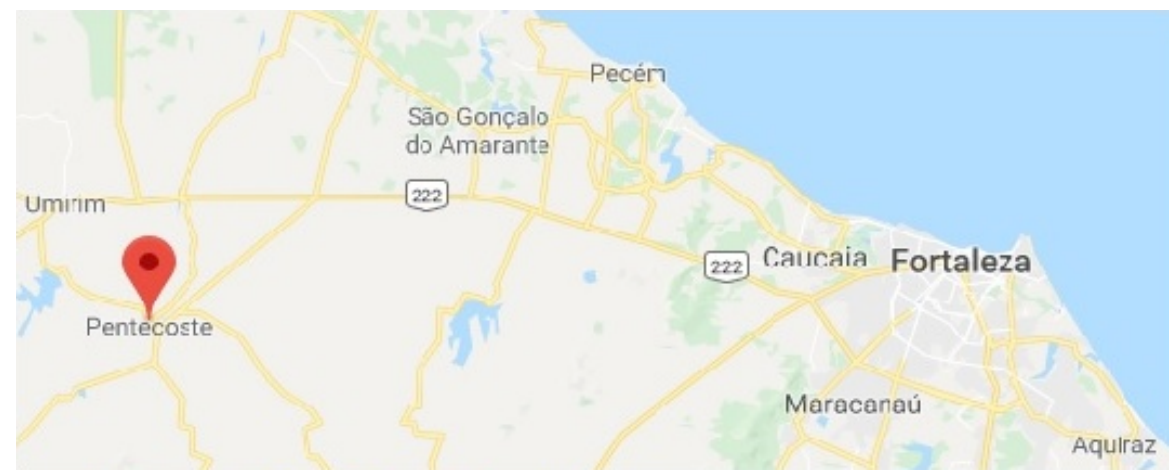

Figura 2 - Localização da cidade de Pentecoste em relação à capital, Fortaleza

Fonte: Google Maps.

A Adel (2017) declara como visão institucional "contribuir para desenvolver comunidades rurais de modo endógeno, enfatizando a sustentabilidade da agricultura familiar, a formação de capital social e a permanência do jovem no campo" (p. 9). Ao longo dos primeiros dez anos de atuação, a Adel cresceu rapidamente e logo começou a dar resultados positivos, atraindo mais jovens como membros e como beneficiários. Dados do mais recente relatório anual da organização dão conta de que, ao longo da primeira década de atuação, a Adel aumentou o seu portfólio de ações para 25 municípios nordestinos, sendo 23 desses no estado do Ceará e 2 no estado do Rio Grande do Norte (Adel, 2017). A estratégia da Adel centra-se em quatro elementos fundamentais: acesso a conhecimento, crédito orientado, redes cooperativas e tecnologias.

Vários são os resultados alcançados que corroboram a afirmação de que a Adel tem conseguido alavancar mudanças positivas nas regiões onde atua. Uma das principais conquistas com os trabalhos realizados pela Adel foi a contribuição para a redução dos índices de êxodo rural na região semiárida cearense por meio do fomento do empreendedorismo local e rural. Conforme o Relatório Anual de 2017 (Adel, 2017), foram registrados 13.004 agricultores apoiados para o desenvolvimento de suas atividades produtivas e comerciais, 2.760 jovens atendidos, 2.029 famílias beneficiadas, 366 comunidades envolvidas, 200 empreendimentos criados e geridos por jovens rurais, $\mathrm{R} \$ 639.276,60$ concedidos em créditos aos jovens pelo Fundo Veredas, e foi identificado um aumento de $70 \%$ na renda familiar dos beneficiários que implementaram seus negócios.

Nesse processo houve, ainda, a formação de quatro arranjos produtivos locais, uma cooperativa e uma companhia de produção agrícola, além da inclusão dos produtos locais da agricultura familiar nos programas de apoio à comercialização, e a estimativa de $\mathrm{R} \$ 385$ mil em valor gerado para os agricultores e jovens empreendedores envolvidos. Arranjos produtivos locais são aglomerações territoriais de agentes econômicos, políticos e sociais que apresentam vínculos, mesmo que incipientes, e que têm como foco um conjunto específico de atividades econômicas (Oliveira \& Martinelli, 2014). Os principais tipos de negócio implementados pelos jovens beneficiados pela Adel são: artesanato (3\%), mecânica (3\%), agricultura (15\%), vestuário (24\%), alimentação (27\%) e beleza (28\%).

Atualmente, a Adel desenvolve as atividades por meio do suporte fornecido por diversos parceiros (Instituto Souza Cruz, Fundação Banco do Brasil, Bolsa de Valores Socioambientais, Programa das Nações Unidas para o Desenvolvimento, Brazil Foundation, Inter-American Foundation, entre outros) e já recebeu 16 prêmios (ao longo de dez anos de atuação) como forma de reconhecimento pela atuação, entre os quais: Prêmio ODM Brasil (2013), Prêmio Fundação Banco do Brasil de Tecnologia Social (2013), Generosidade (2012), Prêmio Nacional de Desenvolvimento Regional (2010) e Prêmio Rosani Cunha de Desenvolvimento Social (2010).

A Adel oferece assessoria técnica, microcrédito, capacitação e gestão de projetos a pequenos empreendimentos e atua por meio de dois programas principais. O primeiro se chama Programa Soluções Rurais e oferece suporte a agricultores e agricultoras familiares de comunidades rurais em situação vulnerável, por 
meio de orientações sobre o uso de técnicas mais eficientes para a melhoria nas condições de produção de frutas, verduras, legumes e criação de animais. O segundo, escolhido como nosso estudo de caso, é o Pjer, que capacita jovens com potencial para serem empreendedores e protagonistas sociais em comunidades rurais, com o objetivo de estimulá-los a desenvolver um negócio, permanecer em suas comunidades e buscar a melhoria da qualidade de vida.

\section{Pjer e suas práticas}

O Pjer foi desenvolvido pela Adel, em 2009, com o objetivo de inserir os jovens nos espaços produtivos, apresentando-Ihes novas alternativas para permanecer e aprender a conviver com os desafios e as oportunidades encontradas na região semiárida nordestina. Sua metodologia foi desenvolvida a partir de um modelo similar usado em um programa do Instituto Souza Cruz. Nas discussões durante as rodas de conversa, desenvolvidas nos trabalhos do Programa Soluções Rurais (voltado a agricultores familiares), os membros da Adel perceberam a ausência dos jovens, fato que os levou a investigar as razões e a propor uma solução para o problema identificado. Ao questionar essa ausência dos jovens, foi possível verificar altos índices de êxodo rural e pouca participação desses sujeitos nas decisões familiares, papel que, em regiões rurais, tradicionalmente costuma ser atribuído ao chefe da família.

Assim, a Adel decidiu direcionar a maior parte de seus esforços no sentido de contribuir para a formação de jovens rurais, dada a importância dessa construção para a mudança da realidade atual e para perspectivas futuras na região. A partir do ano de 2009, a Adel começou a elaborar uma proposta para a juventude. Desde então a ideia passou por ajustes, até se consolidar no modelo atual do Pjer. Para fazer parte do Programa, jovens entre 16 e 32 anos participam de uma seleção composta por entrevista e entrega de documentação. Os jovens selecionados precisam ter definida uma ideia de negócio com o qual gostariam de atuar.

De acordo com o levantamento apresentado na recente Avaliação de Impacto do Pjer no Ceará (20162017), documento elaborado por alunos da Universidade de Columbia e School of International and Public Affairs em um workshop de desenvolvimento econômico e político (Arguinzoni, Bajpai, Cai, Mendiola, \& Ramírez, 2018), desde a sua implementação inicial o Pjer passou por diferentes adaptações. Iniciou com uma formação de 15 semanas de treinamento, durante as quais o foco estava direcionado para aspectos humanos, técnicos e gerenciais, e contemplava 30 participantes a cada seis meses. A partir de 2015, passou a oferecer seis semanas de formação abrangendo conhecimento, rede, crédito, tecnologia social e ambiental para 120 participantes. A partir de 2016 passou a atender 60 participantes por ano.

A metodologia criada para a execução do Pjer segue o fluxo apresentados na Figura 3, na qual está representado o ciclo completo de uma formação. Há, na primeira etapa da formação, um atendimento gratuito a jovens empreendedores rurais com potencial de desenvolvimento selecionados. Na segunda etapa, há uma formação continuada e desenvolvimento dos negócios com serviços oferecidos a esses jovens. Cada um dos seis elementos do ciclo de trabalho do Pjer pode ser caracterizado como uma prática, constituída por grupos sociais, ferramentas e métodos. Entendemos que cada uma destas práticas não acontece sem que grupos sociais mobilizem certo número de ferramentas e métodos, todos muito bem comunicados através de documentos e do website, e também descritos oralmente por meio das entrevistas. Estas práticas formam um conjunto coerente e complementar. Para simplificar a ilustração, escolhemos somente um exemplo de método 
ou ferramenta mobilizados por cada prática, mas estamos cientes de que uma mesma prática pode mobilizar vários métodos e várias ferramentas.

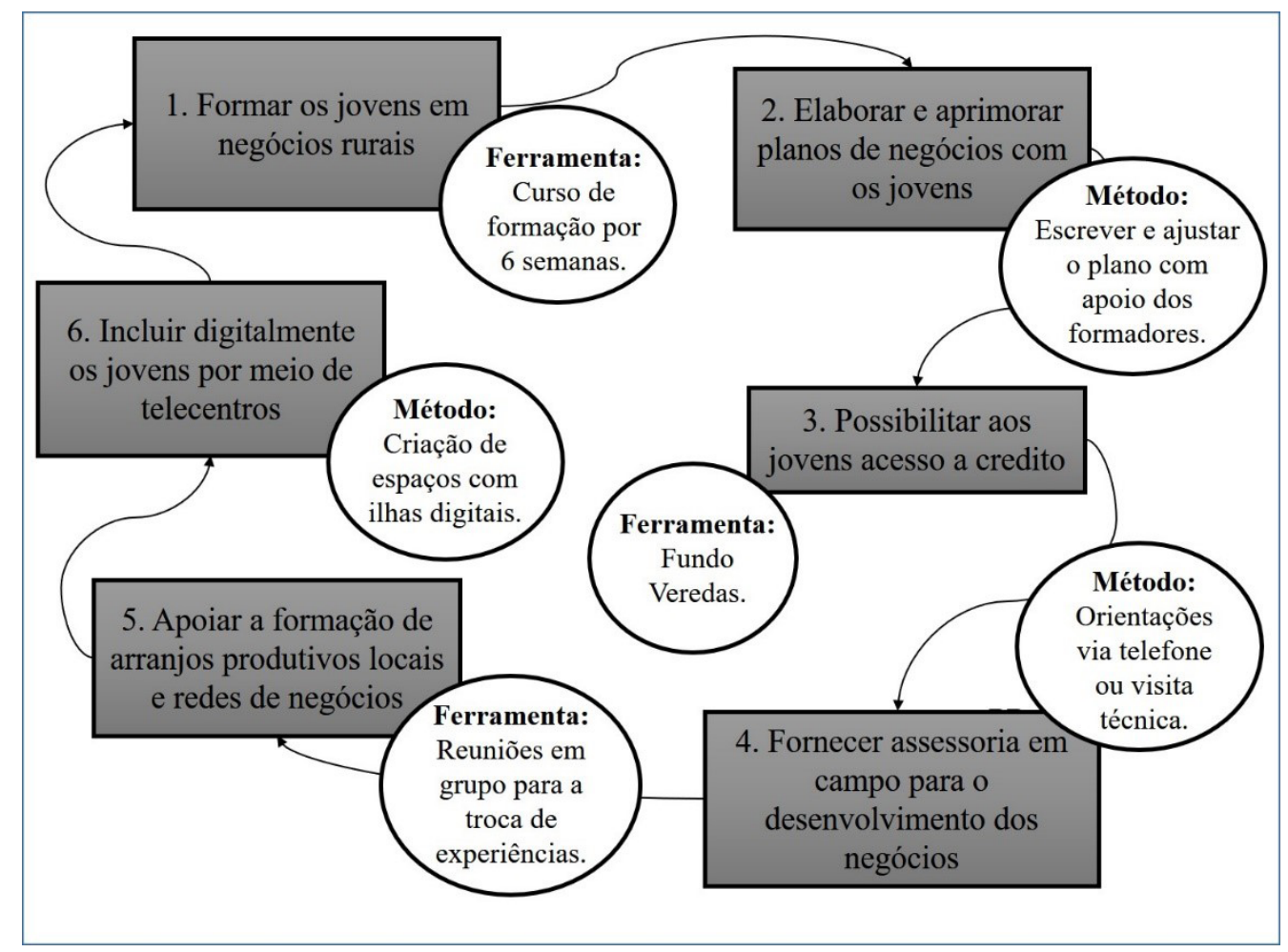

Figura 3 - Ciclo atual de trabalho no Pjer (2017): práticas, métodos e ferramentas

Fonte: Elaborada pelas autoras.

Os grupos sociais são aqueles envolvidos nas etapas de desenvolvimento e operação do Pjer. Foram identificados dois grupos sociais mais importantes. O primeiro é composto pelos membros da Adel: formadores, técnicos, equipe administrativa. O segundo é composto pelos jovens beneficiados e suas famílias, que oferecem suporte à materialização da ideia de negócio pretendida pelos participantes do Pjer.

As ferramentas são os aportes utilizados para a execução de cada uma das práticas. Entre as ferramentas mobilizadas para essas práticas tem-se o curso de formação com duração atual de seis semanas para cada turma selecionada em edital. Nessa formação, há suporte e orientação para a elaboração do plano de negócios; depois que o negócio está configurado para ser implementado, há acesso ao crédito para efetivar o empreendimento; e nas etapas futuras, segue-se com o acompanhamento e suporte técnico dos negócios já implementados, a formação de grupos com jovens beneficiados e os centros físicos de acesso à tecnologia da informação e comunicação. Aulas sobre matemática financeira, gerenciamento de custos, orçamentação, desenvolvimento de produtos, marketing e direito comercial são fundamentais para compartilhar conhecimentos sobre o tema "negócios".

Os métodos dizem respeito à forma como são utilizadas as ferramentas no ciclo de formação. Durante o curso de formação, por exemplo, identificamos o aprendizado sobre técnicas de gestão, as lições sobre empreendedorismo e a importância do trabalho em grupo, por meio do associativismo e da cooperação. $O$ curso de formação mobiliza a pedagogia da alternância, ou seja, os alunos passam um período recebendo lições e um período aplicando o que aprenderam em suas comunidades. Para a elaboração do plano de negócios, com o acompanhamento da equipe de formadores, há um processo de instrução sobre como elaborar o documento que norteará os passos necessários à criação e ao desenvolvimento do empreendimento desejado. 
A constituição do empreendimento é possibilitada pelo acesso ao crédito necessário, que se dá por meio do Fundo Veredas, criado pela Adel utilizando recursos iniciais de um prêmio recebido, com o objetivo de oferecer financiamento desses empreendimentos a custos mais baixos do que os convencionais e com menos entraves documentais. Após a criação do negócio, os beneficiados seguem recebendo suporte para a resolução de problemas. Esse apoio pode ser dado a distância ou com a visita de um técnico ao empreendimento em casos de maior complexidade.

Também para que os jovens beneficiados compartilhem as suas experiências, são incentivados a cultivar a união em grupos e redes, assim, podem trocar informações sobre desafios enfrentados e contornados, oportunidades, novas perspectivas e o que mais julgarem relevante para os demais. Visando também a propagação desse compartilhamento de ideias, foram criados centros integrados de tecnologia, espaços físicos nos quais jovens rurais podem ter acesso à internet e a equipamentos desse universo que são facilitadores de comunicação em uma perspectiva global, como impressoras. Nessa perspectiva, foi criada também uma rede de jovens empreendedores rurais, um espaço de solidariedade entre os jovens no sentido de contribuir para melhor se integrarem em suas comunidades.

Diante desse cenário, sustentamos que a compreensão das práticas, grupos sociais, ferramentas e métodos, que estão subjacentes ao modo de ação de uma tecnologia social, revelam o desencadeamento de uma série de processos individuais e coletivos. Esses processos, imbricados e inter-relacionados, podem variar de um contexto para outro. São eles que nos ajudam a compreender a emergência de transformações sociais - como a inclusão social de um grupo excluído ou o desenvolvimento local de uma comunidade pobre. Nesse sentido, há uma construção que dá suporte às decisões sobre como cada elemento da metodologia deve ser percebido e trabalhado para que se alcance os resultados esperados.

A partir da análise realizada, foram identificados cinco mecanismos-chave da tecnologia social estudada, cuja presença parece fundamental para que haja a transformação social. Essa identificação e compreensão pode facilitar não somente o processo de ajustes e sustentabilidade da tecnologia social no longo prazo, mas também o processo de reaplicação dessa tecnologia em outros contextos. Uma mesma prática, em contextos diferentes, pode produzir resultados distintos. É preciso monitorar e adaptar as práticas para que produzam os efeitos desejados.

\section{Análise dos resultados}

Mecanismos-chave desencadeados pelo programa Pjer

Nesta seção são apresentados os cinco mecanismos-chave (Figura 4) que foram identificados como processos desencadeados pelas práticas do Pjer anteriormente destacadas (Figura 3).

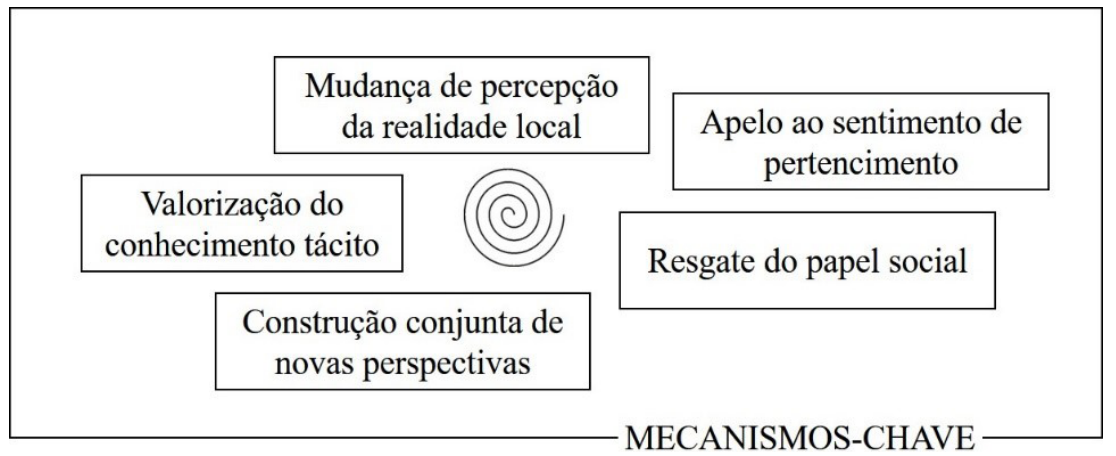

Figura 4 - Cinco mecanismos-chave interdependentes

Fonte: Elaborada pelas autoras. 
Ressaltamos que, apesar de se considerar que os mecanismos identificados, ou terminologias semeIhantes, não são de todo novos nas discussões sobre inovação social ou tecnologia social, seja na literatura ou na descrição de casos, a reunião sistemática desses mecanismos-chave tal como proposto neste trabalho não foi identificada em proposições anteriores. Assim, compreende-se que o sentido de cada um deles é produzido a partir da interação com os outros, não sendo recomendada a leitura isolada de um ou outro, já que é na sua imbricação que se constitui a tecnologia social analisada nesta pesquisa.

O primeiro mecanismo-chave identificado trata da "valorização do conhecimento tácito". Essa valorização do conhecimento alinha-se a algumas definições presentes na literatura, segundo as quais a inovação social pode ser compreendida como o resultado do conhecimento aplicado às necessidades sociais por meio da participação e da cooperação de todos os atores envolvidos (Bignetti, 2011). Nesse sentido, a troca de conhecimento e a valorização da contribuição que pode ser dada por cada indivíduo envolvido na construção de uma inovação social estão na base da constituição desse tipo de iniciativa. Garcia (2014) conecta o significado do termo tecnologia social à criação e utilização de conhecimento por populações desfavorecidas que não tiveram acesso ao conhecimento científico e que perderam condições mais favoráveis à reprodução de seu conhecimento tradicional. A tecnologia social permitiria, então, a promoção da sustentabilidade econômica dessas comunidades, bem como o seu fortalecimento cultural e econômico.

No Pjer, os beneficiados são incentivados a compartilhar as experiências que viveram e a contar histórias da família e de pessoas conhecidas. Essa troca enriquece a formação e complementa os saberes codificados compartilhados pelos facilitadores do curso. Os membros da Adel, ou outros técnicos parceiros, estão sempre abertos a trocar ideias com os habitantes locais, em aprendizado mútuo, em vez de impor esse conhecimento.

A gente não era desconhecida, porque existia um certo preconceito com aquele técnico que eles nunca conheceram. Vinha da universidade, ia até lá dizer o que eles deveriam fazer, que aquela era a melhor técnica, era a melhor saída, a melhor solução e a gente não fazia isso. Primeiro porque eles já conheciam a gente e, segundo, porque a gente buscava fazer um enfoque diferente, dizia assim "Não, gente, que tal vocês utilizarem essa ou outra técnica? Experimentem pra ver, né?". Assim, a gente nunca dizia que aquilo ali era a solução dos problemas deles, como algumas vezes alguns técnicos desinformados chegam a fazer. Então, como a gente conhecia muito bem a realidade, isso geralmente não acontecia, a gente conseguiu fazer isso com certa sintonia com eles, sem causar rejeição logo no início. (Primeiro presidente da Adel, 2013)

Nas nossas visitas de assistência técnica, a gente não chegava impondo o conhecimento da universidade, dos pesquisadores; sempre o nosso trabalho foi mais no diálogo, de tentar casar o conhecimento deles com o que a gente aprendeu na universidade. Isso facilitava o diálogo, a gente partia do princípio de que a gente não sabia de tudo, porque eles tinham o conhecimento deles, conhecimento da prática e tudo, e a ideia da Adel seria melhorar aquilo, tentar trazer algumas coisas para melhorar o que eles já faziam, e não dizer "Vocês estão fazendo errado, o jeito certo é esse aqui". Então, assim, a gente sempre trabalhou nesse sentido, de que a Adel não era uma coisa de fora, a Adel era uma coisa deles, que estava ali para contribuir. (Coordenador do Programa Soluções Rurais,2013)

Logo os jovens [protagonistas da Adel] perceberam que o relacionamento entre a oferta de saberes modernos, com saberes tradicionais acumulados nas próprias comunidades, e a demanda das comunidades por apoio técnico e gerencial para o desenvolvimento local, por conhecimentos e ferramentas adequadas, contextualizadas e sensíveis à sua realidade, possuía um valor agregado. (Adel, 2017, p. 14)

Nos trechos destacados, os jovens membros da Adel tratam da sua origem local e do reconhecimento deles como semelhantes aos beneficiados pela organização, já que, anteriormente à sua formação 
acadêmica, sendo filhos da região, conheciam a realidade local, tinham os mesmos conhecimentos tácitos compartilhados naquele espaço e sabiam da importância desse reconhecimento. Esse mecanismo-chave corrobora a importância da combinação de conhecimentos tácitos e "científicos" e também reforça alguns dos pressupostos colocados por Dagnino (2014), ao tratar de características necessárias às tecnologias sociais, que estas devem ser não discriminatórias, liberadas da diferenciação e libertadoras do potencial do seu produtor direto. É preciso incorporar membros da comunidade, tanto no processo de planejamento quanto de execução, envolvendo os atores locais (Barretto \& Piazzalunga, 2012). A Adel busca extrair e assimilar todo o conhecimento arraigado em seus beneficiários, pois vê na troca a possibilidade de enriquecimento e otimização do objetivo pretendido e compartilhado por todos.

O segundo mecanismo-chave identificado trata da "construção conjunta de novas perspectivas". A formação oferecida pelo Pjer/Adel busca criar uma rede para a troca de conhecimentos gerais e locais que permita aos beneficiários a identificação de novas possibilidades para permanecer na região semiárida, vislumbrando, tanto no núcleo familiar quanto no curso de formação e na aplicação dos conhecimentos adquiridos, perspectivas antes não existentes ou passíveis de identificação devido às limitações existentes nas regiões das quais os beneficiários são oriundos.

E com a formação, com o Pjer, a gente passa a ver o filho conversando mais com o pai, passa a sondar mais, até pelas próprias atividades que vão sendo cobradas ao longo da formação, percebe que precisa da participação da família, né? Por exemplo, tem dados, tem respostas que só os pais podem dar, que só eles conhecem, então tem que ter aquela interação, aquele diálogo. (Coordenadora do Pjer, 2013)

As famílias participam dando suporte aos jovens a partir de esclarecimentos sobre o Pjer e orientações da Adel, oferecidas pelos formadores. O Pjer estimula o trabalho em grupo durante a formação do jovem, desde o curso até o encontro desses jovens nos arranjos produtivos locais criados para compartilhar experiências e nos espaços digitais e físicos de compartilhamento de tecnologias da informação e comunicação.

A cooperação é fator central na fundamentação de uma tecnologia social. Esta é resultado da ação coletiva sobre um processo de trabalho em dado contexto socioeconômico e de um acordo social que enseja controle e cooperação, além de permitir uma modificação no produto gerado, passível de ser apropriada segundo a decisão do coletivo (Dagnino, 2014; Valadão, Cordeiro Neto, \& Andrade, 2017).

Como as tecnologias sociais são concebidas com a participação dos atores locais, conforme ressaltado por essa configuração, destaca a relevância da construção conjunta de novas perspectivas, dado que os atores locais detêm uma série de informações fundamentais ao sucesso dessas iniciativas e que necessitam de estímulo e espaço para aplicação. Nesse sentido, Dagnino (2009) defende a importância de substituição da ideia de que haja uma oferta ou transferência direta de conhecimento da comunidade de pesquisa para a realidade dos excluídos e ressalta a importância do diálogo com associações comunitárias, cooperativas e lideranças locais que possam reunir a comunidade e permitir que, através do diálogo, possam ser identificadas as reais necessidades do contexto em questão.

O terceiro mecanismo-chave ressalta o "apelo ao sentimento de pertencimento". A formação pelo Pjer reúne jovens oriundos de realidades semelhantes e estimula o compartilhamento de experiências e expectativas sobre permanecer em suas comunidades. A equipe da Adel é composta por jovens que compartilham as suas próprias experiências e relatam o que os fez retornar e permanecer em suas localidades de origem. Essa troca instiga os beneficiados a expandir o interesse em contribuir para o desenvolvimento local e também permanecer em suas comunidades.

Eu também não queria vir morar aqui, inclusive quando eu vim em 2009, a minha avó falou comigo, antes de eu vir conhecer a Adel, eu tinha vindo no começo do ano, aí a minha 
avó me chamou para eu vir morar com ela, mas eu disse "Não, vó, eu não tenho intenção de vir morar aqui não". A partir dessas mudanças, dessas novas condições, eu comecei a ver que, principalmente na formação, tanto acreditei que fiz, a mudança foi mais do que eu esperava, na verdade. . . . Eu até pensei muito sobre isso, que sentimento é esse, ficar num lugar que não tem "nada". Mas qual é o sentimento que faz a gente pensar nisso? Na verdade, é uma relação de identidade, você tem uma identidade. (Jovem beneficiado pelo Pjer em 2011, 2013)

Porque a gente sabe que o jovem é um ator muito frágil no sentido de... ele não sabe muito bem o que quer. Por exemplo, ele termina o Ensino Médio, se um tio dele chamar para trabalhar em Fortaleza, se ele não conseguir ver outras oportunidades, ele vai! Ele vai pra São Paulo, vai para outros cantos. Então, de certa forma, a gente precisa envolver um pouco mais a família e a própria comunidade no processo de construção, no processo de "encubação" desse jovem como ator produtivo na própria comunidade. (Diretor-executivo da Adel, 2013)

Santos (2006) destaca que os lugares se situam como intermédio entre o mundo e o indivíduo. O local pode ser o lugar no qual as pessoas estão ligadas pela identidade de pertencimento ou por atividades úteis ao desenvolvimento econômico, social e cultural da coletividade. Esse apelo ao pertencimento permite que aspectos mais globalizantes possam ser considerados, mas sem afetar tão intensamente as particularidades do local.

Para Santos (2006), atualmente o espaço é um sistema de objetos cada vez mais artificiais, povoado por sistemas de ações igualmente imbuídos de artificialidade, com cada vez mais tendência a fins estranhos ao lugar e a seus habitantes. Costa, Bastos, Lima e Silva (2014), ao discorrerem sobre o resgate do sentimento de pertencimento do agricultor pelo labor no campo, proporcionado por outra iniciativa de inovação social no Ceará, destacam a relação entre esse resgate e o prazer no trabalho, no sentido de que o trabalho age como facilitador do prazer, sendo este também constituído pelo reconhecimento e valorização do indivíduo na sociedade.

O quarto mecanismo-chave identificado destaca o "resgate do papel social" e ressalta a relevância de mostrar aos indivíduos o quanto eles podem ser fundamentais para a evolução de suas comunidades. É oferecida ao jovem a oportunidade de aprimorar a atividade desenvolvida pela família ou desenvolver outra atividade e, assim, contribuir para melhoria da qualidade de vida familiar e alcançar a independência financeira, bem como contribuir para o desenvolvimento local.

A educação formal não prepara o jovem que mora no campo para ele morar no campo, ela prepara o jovem que mora no campo para ir para a cidade. Então a Adel preenche esse espaço, não é prendendo, nem segurando o jovem no campo, mas é dando para ele uma visão diferente de viver no campo, como empreendedor, como homem de negócios. (Jovem beneficiado pelo Pjer em 2011, 2013)

Antes, o contexto era que as pessoas sairiam de lá, do meio rural, para vir para cá [Fortaleza], porque aqui era onde você ia ter o trabalho, a renda, aqui era onde você ia ter seu Ensino Superior e aqui você ficava. Hoje, a gente pensa diferente. A gente pensa em ficar lá, pensa em fazer esse trabalho lá. E também os jovens, eles também já pensam diferente, hoje eles já pensam os próprios centros, eles inovam na medida em que eles possibilitam que a comunidade tenha acesso àquele serviço que ele pode oferecer, por exemplo, serviço de telefone, de xerox (cópias), acesso à internet. (Coordenadora de comunicação da Adel, 2013)

A Adel busca, em suas formações, orientar os beneficiários para o lugar social deles, no sentido de despertar esse reconhecimento ou resgatá-lo, caso essa noção tenha sido perdida. Consideramos nesse mecanismo-chave a relevância dada pelos entrevistados ao papel social rural dos jovens em contribuir para 
a melhoria local, quando as melhores oportunidades parecem sempre estar nos grandes centros urbanos. Cria-se um discurso que estimula a migração, eximindo também esses atores locais de desempenhar um papel social diferenciado, que permita uma conjuntura diferente para as suas comunidades. Há, então, a necessidade de mudança no discurso que acentua uma vantagem do êxodo rural sobre a permanência.

Acreditamos que é nessas novas relações sociais que reside a possibilidade de readequação dessa mentalidade. Como destaca Santos (2006), a configuração territorial, ou geográfica, tem uma existência material própria, mas sua existência social, ou seja, a sua existência real, somente the é dada pelo fato das relações sociais. 0 resgate do papel social associa-se diretamente ao empoderamento desses indivíduos. Conforme Moulaert et al. (2013), em inovação social, os processos de empoderamento apresentam-se como um dos meios através dos quais é possível alcançar a inclusão e o bem-estar dos indivíduos. Conforme Andersen et al. (2013), Paulo Freire, ao tratar da habilidade de aprender a compreender as disparidades sociais, políticas e econômicas, e agir contra esses elementos da realidade, trata exatamente do empoderamento das pessoas, elemento caro ao enfrentamento de desafios sociais.

O quinto e último mecanismo-chave identificado em nossa análise trata da "mudança de percepção da realidade local". Para além da formação técnica oferecida pelo Pjer, as discussões sobre educação e política buscam mostrar ao jovem o seu papel na sociedade, a importância e o impacto das suas decisões para as gerações futuras que irão residir nas mesmas comunidades.

Aí depois que eu entrei na Adel, assim, a gente também trabalha com muita reflexão, essas coisas... aí a gente pode ver que o governo é muito pobre nessa questão, ele não supre as necessidades, só trabalha na época da eleição, de dois em dois anos que tem eleição para prefeito e para presidente, aí que eles vão procurar fazer alguma coisa. . . . o trabalho da Adel, eu acho assim, é manter o jovem no campo, né? Ela faz com que o jovem tenha outra visão. (Jovem beneficiado pelo Pjer em 2013, 2013)

Eu percebo o trabalho da Adel com os jovens como algo muito importante. Por exemplo, uma coisa lá na minha comunidade, ela fica aqui a 46 quilômetros da sede do município, fica já vizinho à BR 020 e quase não tem jovem lá, os jovens já foram quase tudo embora para a capital, e a gente vem fazendo esse trabalho para ver se conscientiza o jovem para ele ficar na comunidade. (Agricultor familiar beneficiado pela Adel, 2013)

Nos relatos dados em entrevistas, percebemos o esforço da Adel e o reconhecimento dos beneficiários quanto à construção dessa nova percepção da realidade local. Há uma busca por desconstruir o imaginário de progresso situado longe dessas comunidades rurais. Santos (2006) lembra, sobre a imposição de padrões globais, que o problema consiste em reconhecer o efeito dessas superposições sobre a existência de cada sociedade. A Adel busca orientar seus beneficiários e propagar a partir deles, para as suas comunidades ou além, a ideia de que a realidade local pode ser transformada pelo enfrentamento dos desafios nela presentes e permitir a permanência no lugar de origem acessando boas condições para isso.

Nossos resultados sugerem que os mecanismos-chave identificados, se recriados e ressignificados contextualmente, oferecem sustentação aos elementos componentes do ciclo básico de trabalho do Pjer, pois contribuem para a compreensão do processo de empoderamento das pessoas beneficiadas pela tecnologia social explorada. No caso das práticas do Pjer/Adel, observa-se que o programa tem mais do que um ciclo, que são de alguma forma cumulativos e dinâmicos. Essas práticas desencadeiam uma série de mecanismos-chave, e estes não são sequenciais ou lineares, mas cíclicos e interdependentes (Figura 5). 


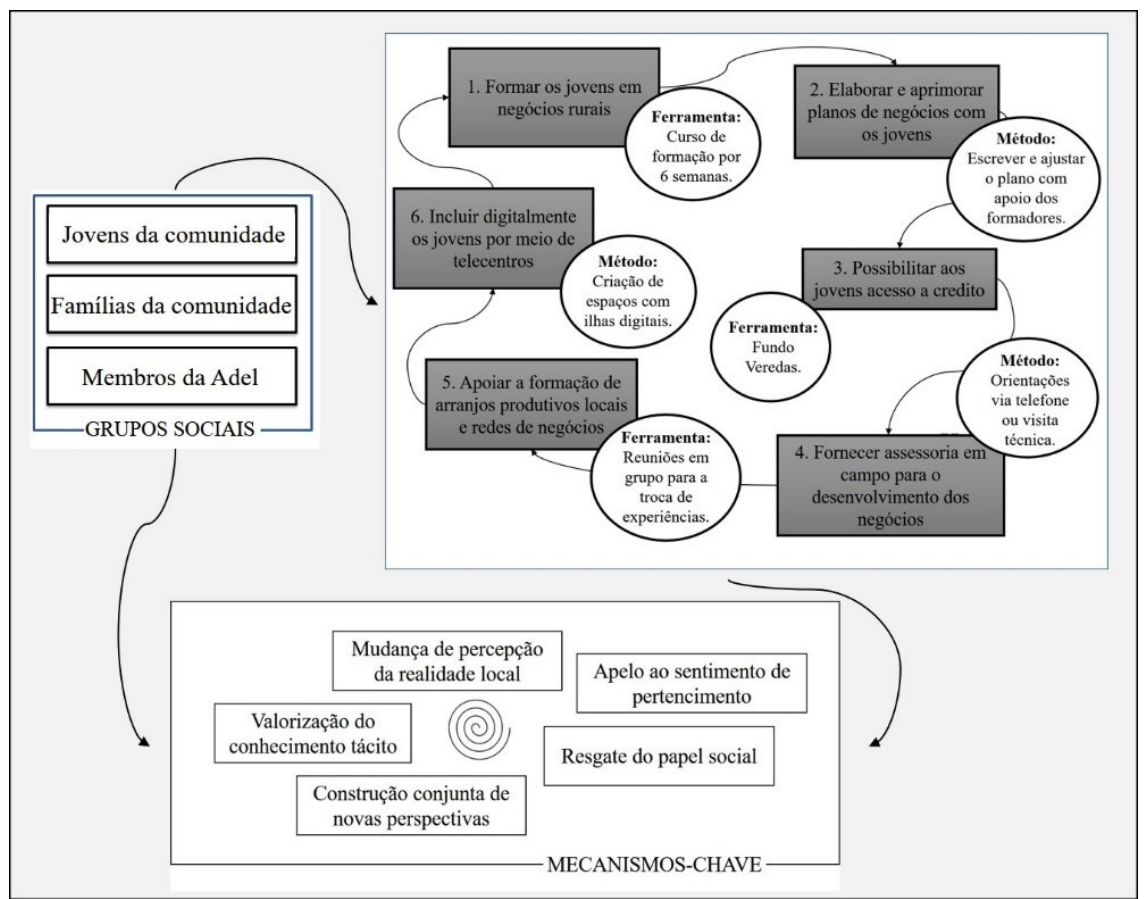

Figura 5 - Tecnologia social e transformação social: práticas e mecanismos-chave

Fonte: Elaborada pelas autoras.

As práticas do Pjer, mobilizadas por seus grupos sociais, ferramentas e métodos, desencadeiam mecanismos-chave particulares à cada tecnologia social estudada e a cada contexto. Esses mecanismos-chave auxiliam a promover transformações sociais, mas não de forma determinista. Essas transformações sociais são socialmente construídas pelos atores sociais, nas quais promotores e beneficiários são todos protagonistas.

O modelo conceitual proposto neste trabalho contribui tanto para a literatura em inovação quando para a literatura em tecnologia social. Conforme salientamos no início deste trabalho, entre as maiores lacunas enfrentadas pelos promotores de programas de inovação social estão a sustentabilidade ou perenidade no longo prazo e a transferibilidade ou replicação desses programas. Argumentamos que abrir a "caixa preta" de um programa de inovação social e compreender sua "anatomia", ou seja, a articulação dos seus componentes fundamentais, representa um passo importante para sua compreensão. Essa compreensão favorece a implementação de medidas que levem a ajustes finos e a uma maior perenidade ao longo do tempo. A identificação destes elementos - práticas, métodos, ferramentas e mecanismos-chave - permite também um maior suporte aos processos de reaplicação desses elementos em um novo contexto, com todas as ressignificações e adaptações necessárias.

O modelo também contribui para a literatura em tecnologia social, porque percebe-se uma certa escassez de modelos teóricos mais robustos. Acreditamos que nosso modelo é o embrião de um processo de teorização das tecnologias sociais que será refinado nos próximos trabalhos.

\section{Considerações finais}

Esta pesquisa busca no conceito de tecnologia social, elaborado por pesquisadores sulamericanos, uma lente teórica para fazer avançar nosso conhecimento sobre os caminhos que levam a transformações sociais. Thomas (2009) lembra que a reflexão sobre a relação entre tecnologia e pobreza é fundamental para o futuro da América Latina. A partir da lente das tecnologias sociais, buscamos identificar as práticas 
centrais e os mecanismos-chave desencadeados por elas para compreender como uma transformação social é alavancada. Com estes resultados, buscamos responder a nossa questão de pesquisa - Quais são os mecanismos-chave colocados em prática por uma tecnologia social que ajudam a promover as transformações sociais desejadas localmente? Argumentamos que a identificação e sistematização desses mecanismos-chave são fundamentais para melhor compreender o modo de ação de uma tecnologia social e, assim, poder não somente contribuir para sua perenidade no tempo, como também reaplicá-la para além do contexto na qual foi concebida. Considerou-se, para a exploração do caso escolhido, a transformação social favorecida pela tecnologia social do Pjer, agindo na região semiárida cearense, especialmente no que diz respeito à redução do êxodo rural de jovens. Em Pentecoste, esses jovens estão vivendo um processo de empoderamento através da inter-relação de uma série de mudanças, de mecanismos-chave, que os permitem vislumbrar a possibilidade de permanecer em suas comunidades, empreender e contribuir para o desenvolvimento local.

Para finalizar, gostaríamos de compartilhar algumas das reflexões inspiradas pelos resultados deste estudo. Há, nas tecnologias sociais, caracteres imbricados que necessitam de um envolvimento anterior à sua reaplicação, no sentido de ouvir os atores envolvidos e buscar extrair de seus relatos elementos que constituem a base de sucesso da iniciativa analisada. Embora a tecnologia social possa parecer diretamente reaplicável em contextos julgados extremamente semelhantes, ainda assim será possível identificar nos atores e nas dinâmicas de cada lugar particularidades fundamentais que poderão comprometer a implementação da mesma iniciativa. Para Barretto e Piazzalunga (2012), a inserção da comunidade como construtora da tecnologia social, e não apenas beneficiária, é necessária porque existem questões relacionadas à apropriação tecnológica e à autonomia que são essenciais para posterior reaplicação, que não podem ser resolvidas em laboratórios nem a partir de modelos teóricos.

O processo de identificação dos grupos sociais envolvidos, das práticas, ferramentas e métodos que as compõem, bem como a identificação dos mecanismos-chave a eles subjacentes, representa um caminho na busca de uma compreensão mais profunda das particularidades de uma tecnologia social. Desenhar esse processo significa pensar a tecnologia social conceitualmente e, assim, permitir uma projeção de caminhos necessários à reaplicação em outros contextos. Uma das limitações deste estudo é a ausência de uma análise mais crítica, tal como referenciada no posicionamento teórico (construtivismo crítico).

Essa ausência de uma análise mais crítica pode ser explicada pela natureza da questão de pesquisa que norteou esta parte do nosso projeto - identificar quais são os mecanismos-chave colocados em prática por uma tecnologia social. Este estudo faz parte de um programa de pesquisa mais amplo, e seus resultados dão apenas um primeiro passo na direção de uma compreensão mais profunda das tensões e paradoxos que permeiam a transformação social. A Adel segue implementando o Pjer em outras comunidades da região na qual atua, com atenção às particularidades de cada localidade, pois embora estejam na região semiárida e enfrentando desafios semelhantes, essa atenção é fundamental para que o programa alcance seu objetivo fundante de empoderamento da juventude rural.

\section{Referências}

Agência de Desenvolvimento Econômico Local. (2017). Relatório anual 2017. Recuperado de http://bit.ly/ 39PhlhR

Agostini, M. R., Vieira, L. M., \& Bossle, M. B. (2016). Social innovation as a process to overcome institutional voids: A multidimensional overview. Revista de Administração Mackenzie, 17(6), 72-101. doi:10.1590/1678-69712016/administracao.v17n6p72-101

Agostini, M. R., Vieira, L. M., Tondolo, R. R. P., \& Tondolo, V. A. G. (2017). Uma visão geral sobre a pesquisa em inovação social: Guia para estudos futuros. Brazilian Business Review, 14(4), 385402. doi:10.15728/bbr.2017.14.4.2 
Albuquerque, L. C. (2009). Tecnologias sociais ou tecnologias apropriadas? O resgate de um termo. In A. Otterloo (Ed.), Tecnologias sociais: Caminhos para a sustentabilidade (pp. 15-24). Brasília, DF: Rede de Tecnologia Social.

Alvesson, M., \& Sköldberg, K. (2000). Reflexive methodology: New vistas for qualitative research. London: Sage.

Andersen, J., Delica, K., \& Fradsen, M. (2013). From "book Container" to community centre. In F. Moulaert, D. MacCallum, A. Mehmood, \& A. Hamdouch (Eds.), The international handbook on social innovation: Collective action, social learning and transdisciplinary research (pp. 197-206). Cheltenham: Edward Elgar.

Andion, C., Ronconi, L., Moraes, R. L., Gonsalves, A. K. R., \& Serafim, L. B. D. (2017). Sociedade civil e inovação social na esfera pública: Uma perspectiva pragmatista. Revista de Administração Pública, 51(3), 369-387. doi:10.1590/0034-7612143195

Andrade, J. A., \& Valadão, J. A. D. (2017). Análise da instrumentação da ação pública a partir da teoria do ator-rede: Tecnologia social e a educação no campo em Rondônia. Revista de Administração Pública, 51(3), 407-430. doi:10.1590/0034-7612153318

Arguinzoni, O., Bajpai, S., Cai, T., Mendiola, G., \& Ramírez, S. (2018). Avaliação do impacto do Programa Jovens Empreendedores Rurais no Ceará, Brasil. Recuperado de http://bit.ly/325vt9G

Barbosa, L. G. M., \& Rezende, C. (2008). Observatório de Inovação Social do Turismo: 0 envolvimento da academia, governo e sociedade civil organizada no combate à exploração sexual de crianças e adolescentes no turismo. Revista Acadêmica do Observatório de Inovação do Turismo, 3(3), 1-14. Recuperado de http://bit.ly/2vlbd1K

Barretto, S. F. A., \& Piazzalunga, R. (2012). Tecnologias sociais. Ciência e Cultura, 64(4), 4-5. doi:10.21800/ S0009-67252012000400002

Bignetti, L. P. (2011). As inovações sociais: Uma incursão por ideias, tendências e focos de pesquisa. Ciências Sociais Unisinos, 47(1), 3-14. doi:10.4013/csu.2011.47.1.01

Bitencourt, C. C., Marconatto, D. A. B., Cruz, L. B., \& Raufflet, E. (2016). Introduction to special edition social innovation: Researching, defining and theorizing social innovation. Revista de Administração Mackenzie, 17(6), 14-19. Recuperado de http://bit.ly/2SOG30o

Bonilha, M. C., \& Sachuk, M. I. (2011). Identidade e tecnologia social: Um estudo junto às artesãs da Vila Rural Esperança. Cadernos EBAPE.BR, 9(2), 412-437. doi:10.1590/S1679-39512011000200011

Bradach, J. (2003, primavera). Going to scale: The challenge of replicating social programs. Stanford Social Innovation Review. Recuperado de http://bit.ly/2v1VHhh

Brunstein, J., Rodrigues, A. L., \& Kirschbaum, C. (2008). Inovação social e empreendedorismo institucional: A ação da ONG "Ação Educativa" no campo educacional da cidade de São Paulo. Organizações \& Sociedade, 15(46), 119-136. doi:10.1590/S1984-92302008000300006

Campos, I. M., \& Davel, E. (2017). Identidade, arte e gestão em prol do empreendedorismo cultural: Sarau empreendedor como tecnologia social. Race: Revista de Administração, Contabilidade e Economia, 16(2), 783-808. doi:10.18593/race.v16i2.13270

Cavalcante, L. E. (2011). Informação, inovação social e condições de vida: Construindo competências para o desenvolvimento sustentável. Revista EDICIC, 1(2), 302-316. Recuperado de http://bit.ly/2uWQbfG

Correia, S. N., Oliveira, V. M., \& Gómez, C. P. (2016). Dimensions of social innovation and the roles of organizational actor: The proposition of a framework. Revista de AdministraçãoMackenzie, 17(6), 102-133. doi:10.1590/1678-69712016/administracao.v17n6p102-133 
Correia-Lima, B. C. C., Costa, J. S., Cabral, A. C. A., Silva, J. C. L., Filho, \& Santos, S. M. (2013). Humor no Ceará como inovação social: Uma análise do ambiente técnico e institucional. Gestão \& Sociedade, 7(18), 343-368. doi:10.21171/ges.v7i18.1836

Costa, J. S., Bastos, G. M. F., Lima, B. C. C., \& Silva, J. C. L., Filho (2014). Inovação social, prazer e sofrimento no trabalho: $O$ caso do Projeto Mandalla no Ceará. Administração Pública e Gestão Social, 6(1), 11-18. Recuperado de http://bit.ly/2vPAs2o

Costa, S. P. B., \& Vidal, F. A. B. (2008). Tecnologia social de inclusão de jovens pelo trabalho: Uma análise da experiência de um consórcio de ONGs no desenvolvimento de ação intersetorial com empresas e governo. Gestão \& Regionalidade, 24(71), 19-30. Recuperado de http://bit.ly/2vPT8yE

Creswell, J. (2010). Projeto de pesquisa: Métodos qualitativo, quantitativo e misto (3a ed.). Porto Alegre, RS: Artmed.

Dagnino, R. (Org). (2009). Tecnologia social: Ferramenta para construir outra sociedade. Recuperado de http://bit.ly/326Bz9l

Dagnino, R. (2011). Tecnologia social: Base conceitual. Ciência \& Tecnologia Social, 1(1), 1-12. Recuperado de http://bit.ly/37MfNJS

Dagnino, R. (2014). A tecnologia social e seus desafios. In Tecnologia social: Contribuições conceituais e metodológicas (Vol. 2, pp. 19-34). Recuperado de http://books.scielo.org/id/7hbdt

Dickson, D. (1974). Alternative technology and the politics of technical change. London: Fontana.

Diogo, V., \& Guerra, P. (2013). A inovação social como utopia renovada: O caso da Associação Humanitária Habitat. Sociologia, 25, 141-163. Recuperado de http://bit.ly/2SVQjUJ

Duque, T. O., \& Valadão, J. A. D. (2017). Abordagens teóricas de tecnologia social no Brasil. Revista Pensamento Contemporâneo em Administração, 11(5), 1-19. doi:10.12712/rpca.v11i5.962

Feenberg, A. (2002). Transforming technology: A critical theory revisited. Oxford: Oxford University Press.

Félix, W. J. S., Quirino, R. H. R., Grangeiro, R. R., \& Silva, J. T., Jr. (2009). A relação entre tecnologia social e o desenvolvimento local participativo: a Apaeb e o Instituto Palmas como expressão destes vínculos. Revista ADM.MADE, 13(2), 16-33. Recuperado de http://bit.ly/329ZV2u

Franzoni, G. B., \& Silva, T. N. (2016). Inovação social e tecnologia social: O caso da cadeia curta de agricultores familiares e a alimentação escolar em Porto Alegre/RS. Desenvolvimento em Questão, 14(37), 353-386. doi:10.21527/2237-6453.2016.37.353-386

Freitas, C. C. G., \& Segatto, A. P. (2014). Ciência, tecnologia e sociedade pelo olhar da tecnologia social: Um estudo a partir da teoria crítica da tecnologia. Cadernos EBAPE.BR, 12(2), 302-320. doi:10.1590/167939517420

Garcia, S. G. (2014). A tecnologia social como alternativa para a reorientação da economia. Estudos Avançados, 28(82), 251-275. doi:10.1590/S0103-40142014000300015

Glesne, C. (1999). Becoming qualitative researchers: An introduction (2a ed.). New York: Longman.

Gregoire, M. (2016). Exploring various approaches of social innovation: A francophone literature review and a proposal of innovation typology. Revista de Administração Mackenzie, 17(6), 45-71. doi:10.1590/167869712016/administracao.v17n6p45-71

Herrera, A. (1983). Transferencia de tecnología y tecnologías apropiadas: contribución a una visión prospectiva a largo plazo. Campinas, SP: Editora da Unicamp. 
Ipiranga, A. S. R., Amorim, M. A., \& Faria, M. V. C. M. (2007). Tecnologia social de mobilização para arranjos produtivos locais: Uma proposta de aplicabilidade. Cadernos EBAPE.BR, 5(3), 123. doi:10.1590/ S1679-39512007000300011

Jecquier, N. (1976). Appropriate technology: problems and promises. Paris: OECD Publications.

Jiménez, D. R., \& Lora, P. (2016). La innovación social como transformación de comunidades: El modelo del Parque Científico de Innovación Social - Colombia. NAVUS: Revista de Gestão e Tecnologia, 6(4), 88-97. Recuperado de http://bit.ly/3bMXsQ5

Kohr, L. (1981). Tecnología adecuada. In R. D. Laind, A. Lovins, I. Illich, J. Michell, F. Capra, \& E. Bono (Eds.), Para Schumacher (pp. 207-216). Madrid: H. Blume Ediciones, Madrid.

Medeiros, C. B., Galvão, C. E. S., Correia, S., Gómez, C., \& Castillo, L. (2017). Inovação social além da tecnologia social: Constructos em discussão. Race: Revista de Administração, Contabilidade e Economia, 16(3), 957-982. doi:10.18593/race.v16i3.13606

Medeiros, C. B., Machado, L. C. R., Pereira, L. C. A., Costa, I. C. A., \& Gomez, C. P. (2017). Inovação social e empreendedorismo social: Uma análise sob a perspectiva da economia solidária. Revista Gestão.Org, 15(1), 61-72. doi:10.21714/1679-18272017v15n1.p61-72

Mendell, M. (2016, 7 julho). Now is the time for social innovation. Policy Options. Recuperado de http://bit.ly/2SWrw2R

Menezes, A. G., Lezana, A. G. R., Ronconi, L. F. A., Menezes, E. C. O., \& Melo, E. N. (2016). A pesquisa-ação como estratégia de avaliação da inovação social: Estudo de uma entidade educacional do município de Florianópolis. Navus: Revista de Gestão e Tecnologia, 6(2), 93-105. doi:10.22279/navus.2016.v6n2.p93-105.367

Miles, M. B., \& Huberman, A. M. (2004). Qualitative data analysis: An expanded sourcebook. Thousand Oaks: Sage.

Miranda, I., Lopez, M., \& Soares, M. C. C. (2011). Social technology network: Paths for sustainability. Innovation and Developement, 1(1), 151-152. doi:10.1080/2157930X.2011.556470

Moulaert, F., MacCallum, D., Mehmood, A., \& Hamdouch, A. (Eds). (2013). The international handbook on social innovation: Collective action, social learning and transdisciplinary research. Northampton: Edward Elgar Pub.

Mumford, L. (1964). Authoritarian and democratic technics. Technology and Culture, 5(1), 1-8. Recuperado de http://bit.ly/3cOW4JI

Mussi, C. C., Faraco, R. A., Angeloni, M. T., \& Peres, F. M. (2013). Rede social para transferência de conhecimento e inovação social. Revista Pensamento Contemporâneo em Administração, 7(4), 77-97. Recuperado de http://bit.ly/38FEk4w

Neder, R. T., \& Thomas, H. (2010). The movement for social technology in Latin-America. Recuperado de http://bit.ly/2V4PjjV

Nunes, N. A., Casagrande, J. L., Ramos, M. M. G., Santos, A. A. P., \& Corseuil, L. (2017). Participação comunitária como prática de inovação social: Um estudo de caso no Centro Educacional Marista Lúcia Mayvorne. Revista Eletrônica de Estratégia \& Negócios, 10(2), 154-180. doi:10.19177/ reen.v10e22017154-180

Oliveira, A. G. M., Melo, M. C. O. L., \& Muylder, C. F. (2016). Educação empreendedora: O desenvolvimento do empreendedorismo e inovação social em instituições de ensino superior. Revista Administração em Diálogo, 18(1), 29-56. doi:10.20946/rad.v18i1.12727 
Oliveira, M. F., \& Martinelli, D. P. (2014). Desenvolvimento local e arranjos produtivos locais: Uma revisão sistemática da literatura. Interações, 15(1), 47-58. doi:10.1590/S1518-70122014000100005

Oliveira, N. D. A., \& Silva, T. N. (2012). Inovação social e tecnologias sociais sustentáveis em relacionamentos intercooperativos: Um estudo exploratório no Creditag-RO. Revista de Administração da UFSM, 5(2), 277-295. Recuperado de http://bit.ly/2vQInO4

Patias, T. Z., Bobsin, D., Gomes, C. M., Liszbinski, B. B., \& Damke, L. I. (2016). Family agro-industry clusters from the social innovation perspective. Revista de Administração Mackenzie, 17(6), 191215. doi:10.1590/1678-69712016/administracao.v17n6p191-215

Patias, T. Z., Gomes, C. M., Oliveira, J. M., Bobsin, D., \& Liszbinski, B. B. (2017). Modelos de análise da inovação social: 0 que temos até agora? Revista Brasileira de Gestão e Inovação, 4(2), 125147. doi:10.18226/23190639.v4n2.07

Pinheiro, G. F., Neto, \& Abreu, M. C. S. (2015). Inovação social em um empreendimento econômico solidário: alternativas para o enfrentamento da marginalização. Revista de Administração Hospitalar e Inovação em Saúde, 12(2), 1-18. doi:10.21450/rahis.v12i2.2366

Quirino, B. S., Alvarenga, R. C. D., Neto, Carvalho, R. B., \& Goulart, I. B. (2015). Análise do Programa Habitacional Minha Casa, Minha Vida nas perspectivas da inovação social e a evolução das políticas públicas. Revista de Gestão Social e Ambiental, 9(3), 97-117. Recuperado de http://bit.ly/390tQQe

Ribeiro, E. C. M., \& Silva, M. M. C. (2010). Um retrato do semiárido cearense. Recuperado de http://bit.ly/2P7xdd4

Ribeiro, R. E. M., Segatto, A. P., \& Coelho, T. R. (2013). Inovação social e estratégia para a base da pirâmide: Mercado potencial para empreendedores e pequenos negócios. Regepe, 2(2), 55-72. doi:10.14211/ regepe.v2i 2.61

Riskin, K. (1983). La tecnología intermedia de las industrias rurales de China. In A. Robinson, (Ed.), Tecnologías apropiadas para el desarrollo del tercer mundo (pp. 75-100). Ciudad de México: FCE.

Rodrigues, A. L., Kozonoi, N., \& Arruda, F. A. M. (2012). Organizações sociais: um estudo de caso sobre possibilidades e limitações da geração de inovação social pela Osesp. Gestão.Org, 10(2), 344-368. Recuperado de http://bit.ly/2Q7n1Ce

Rodrigues, I., \& Barbieri, J. C. (2008). A emergência da tecnologia social: Revisitando o movimento da tecnologia apropriada como estratégia de desenvolvimento sustentável. Revista de Administração Pública, 42(6), 1069-1094. doi:10.1590/S0034-76122008000600003

Santos, M. (2006). A natureza do espaço: Técnica e tempo, razão e emoção. São Paulo, SP: Hucitec.

Schumacher, E. F. (1973). Small is beautiful: Economics as if people mattered. New York: Harper and Row.

Smith, A., Fressoli, M., Abrol, D., Arond, E., \& Ely, A. (2017). Grassroots innovation movements: Pathways to sustainability. New York: Routledge.

Smith, A., Fressoli, M., \& Thomas, H. (2014). Grassroots innovation movements: Challenges and contributions. Journal of Cleaner Production, 63, 114-124. doi:10.1016/j.jclepro.2012.12.025

Stake, R. E. (2005). Qualitative case studies. In N. K. Denzin, \& Y. S. Lincoln (Eds.), The Sage handbook of qualitative research (3a ed., pp. 443-466). London: Sage.

Thomas, H. (2009). Tecnologías para la inclusión social y políticas públicas en América Latina. In: A. Otterloo (Ed.), Tecnologias sociais: Caminhos para a sustentabilidade (pp. 25-81). Brasília, DF: Rede de Tecnologia Social. 
Valadão, J. A. D., Andrade, J. A., \& Cordeiro, J. R., Neto (2014). Abordagens sociotécnicas e os estudos em tecnologia social. Pretexto, 15(1), 44-61. Recuperado de http://bit.ly/38Jfvo6

Valadão, J. A. D., Cordeiro, J. R., Neto, \& Andrade, J. A. (2017). Bases sociotécnicas de uma tecnologia social: O transladar da pedagogia da alternância em Rondônia. Organizações \& Sociedade, 24(80), 89-114. doi:10.1590/1984-9230805

Vazquez Maguirre, M., Camacho Ruelas, G., \& Garcia Torre, C. (2016). Women empowerment through social innovation in Indigenous social enterprise. Revista de Administração Mackenzie, 17(6), 164-190. doi:10.1590/1678-69712016/administracao.v17n6p164-190

Vieira, N. S., Barbosa, A. C. Q., Parente, C. C. R., \& Lopes, D. P. T. (2018). Contribution to social innovation theory and practice: Lessons from a Portuguese association. Administração Pública e Gestão Social, 10(1), 12-21. Recuperado de http://bit.ly/2vLGWPB

Webber, G., \& Ferreira, M. R. (2015). A tecnologia social e a interface com a gestão ambiental: Desafios contemporâneos. Revista Interdisciplinar de Gestão Social, 4(2), 33-40. Recuperado de http://bit.ly/328gjR7

\section{Agradecimentos}

Este trabalho foi realizado com apoio da Coordenação de Aperfeiçoamento de Pessoal de Nível Superior - Código de Financiamento 001.

\section{Sobre os Autores}

\section{Ana Clara Aparecida Alves de Souza}

Doutora em administração pela Universidade Federal do Rio Grande do Sul. Faz estágio pós-doutoral no Programa de Pós-Graduação em Administração da Pontifícia Universidade Católica do Rio Grande do Sul. Pesquisa e publica sobre inovação social, tecnologias sociais, economia compartilhada e consumo colaborativo, empreendedorismo social e organizações híbridas. E-mail: ana.c.souza@pucrs.br. ORCID: 0000-0001-5574-2560

\section{Marlei Pozzebon}

Doutora em administração pela McGill University, Canadá. Professora titular na HEC Montreal, Canadá, e na Escola de Administração de Empresas de São Paulo da Fundação Getulio Vargas. Pesquisa e publica sobre a relação entre tecnologia e sociedade, tecnologias sociais, projetos de base comunitária e abordagens do pós desenvolvimento. E-mail: marlei.pozzebon@hec.ca. ORCID: 0000-0001-5380-908X 


\section{Apêndice}

Quadro1 - Artigos disponíveis no sistema de indexação Spell contendo no título os termos "inovação social" e "tecnologia social" (maio, 2018)

\begin{tabular}{|c|c|c|}
\hline Tema principal & Descrição & Autores \\
\hline $\begin{array}{l}\text { Inovação social, } \\
\text { tecnologia social } \\
\text { e organizações } \\
\text { sociais }\end{array}$ & $\begin{array}{l}\text { Estudos que relacionam inovação } \\
\text { social (IS) ou tecnologia social (TS) a } \\
\text { organizações sociais, organizações não } \\
\text { governamentais, arranjos produtivos } \\
\text { locais, fundações, bibliotecas } \\
\text { comunitárias para inclusão informacional, } \\
\text { erradicação da pobreza habitacional. }\end{array}$ & $\begin{array}{l}\text { Brunstein, Rodrigues e Kirschbaum (2008) } \\
\text { Cavalcante (2011) } \\
\text { Costa e Vidal (2008) } \\
\text { Diogo e Guerra (2013) } \\
\text { Patias, Bobsin, Gomes, Liszbinski e Damke (2016) } \\
\text { Rodrigues, Kozoni e Arruda (2012) }\end{array}$ \\
\hline $\begin{array}{l}\text { Inovação social e } \\
\text { política }\end{array}$ & $\begin{array}{l}\text { Estudos que investigam programas } \\
\text { habitacionais, IS para agricultura } \\
\text { familiar no semiárido, políticas de IS e } \\
\text { desenvolvimento, turismo e exploração } \\
\text { sexual, economia solidária e vazios } \\
\text { institucionais. }\end{array}$ & $\begin{array}{l}\text { Agostini, Vieira e Bossle (2016) } \\
\text { Barbosa e Rezende (2008) } \\
\text { Costa et al. (2014) } \\
\text { Pinheiro Neto e Abreu (2015) } \\
\text { Quirino, Alvarenga Neto, Carvalho e Goulart (2015) }\end{array}$ \\
\hline $\begin{array}{l}\text { Casos de inovação } \\
\text { social e tecnologia } \\
\text { social }\end{array}$ & $\begin{array}{l}\text { Casos envolvendo aplicação do } \\
\text { conceito de TS, experiências de TS e } \\
\text { desenvolvimento local, identidade e TS, } \\
\text { parques científicos, cooperativas, cadeias } \\
\text { de agricultores, permacultura; TS e } \\
\text { educação no campo, centro educacional e } \\
\text { uma associação portuguesa. }\end{array}$ & $\begin{array}{l}\text { Andrade e Valadão (2017) } \\
\text { Bonilha e Sachuk (2011) } \\
\text { Costa et al. (2014) } \\
\text { Félix, Quirino, Grangeiro e Silva Jr. (2009) } \\
\text { Franzoni e Silva (2016) } \\
\text { Jiménez e Lora (2016) } \\
\text { Nunes et al. (2017) } \\
\text { Oliveira e Silva (2012) } \\
\text { Rodrigues e Barbieri (2008) } \\
\text { Vieira, Barbosa, Parente e Lopes (2018) }\end{array}$ \\
\hline $\begin{array}{l}\text { Inovação social, } \\
\text { tecnologia social e } \\
\text { empreendedorismo }\end{array}$ & $\begin{array}{l}\text { Estudos que investigam empreendimentos } \\
\text { e negócios para a base da pirâmide, } \\
\text { educação empreendedora no Ensino } \\
\text { Superior, sarau empreendedor como TS, } \\
\text { e economia solidária. }\end{array}$ & $\begin{array}{l}\text { Campos e Davel (2017) } \\
\text { Medeiros, Machado, Pereira, Costa e Gomez (2017) } \\
\text { Oliveira, Melo e Muylder (2016) } \\
\text { Ribeiro, Segatto e Coelho (2013) }\end{array}$ \\
\hline $\begin{array}{l}\text { Discussões teóricas } \\
\text { sobre inovação } \\
\text { social }\end{array}$ & $\begin{array}{l}\text { Estudos que focalizam a base conceitual } \\
\text { para a TS, pesquisa-ação como estratégia } \\
\text { para a análise da IS, um olhar para a TS } \\
\text { a partir da teoria crítica da tecnologia; } \\
\text { análise da literatura francófona de } \\
\text { abordagens sobre IS; perspectivas } \\
\text { sociotécnicas como base para a TS; IS } \\
\text { como novo paradigma para a inovação, } \\
\text { necessidade de discussão da IS a partir } \\
\text { da sociologia e da ciência política com } \\
\text { foco na esfera pública e modelos de } \\
\text { análise da IS, a concepção de IS e TS, } \\
\text { e análise da produção acadêmica em IS } \\
\text { durante cinco anos. }\end{array}$ & $\begin{array}{l}\text { Agostini, Vieira, Tondolo e Tondolo (2017) } \\
\text { Andion et al. (2017) } \\
\text { Bitencourt et al. (2016) } \\
\text { Dagnino (2011) } \\
\text { Freitas e Segatto (2014) } \\
\text { Garcia (2014) } \\
\text { Gregoire (2016) } \\
\text { Medeiros, Galvão, Correia, Gómez e Castillo (2017) } \\
\text { Menezes, Lezana, Ronconi, Menezes e Melo (2016) } \\
\text { Patias, Gomes, Oliveira, Bobsin e Liszbinski (2017) } \\
\text { Valadão, Andrade e Cordeiro Neto (2014) }\end{array}$ \\
\hline $\begin{array}{l}\text { Outros temas } \\
\text { relacionados com } \\
\text { inovação social ou } \\
\text { tecnologia social }\end{array}$ & $\begin{array}{l}\text { Estudos que analisam a TS para a } \\
\text { mobilização de agentes em arranjos } \\
\text { produtivos locais, humor como IS, } \\
\text { redes sociais para transferência de IS, } \\
\text { interface entre TS e gestão ambiental, } \\
\text { empoderamento feminino e dimensões } \\
\text { da IS, o papel do ator organizacional, e } \\
\text { estudo bibliométrico sobre TS. }\end{array}$ & $\begin{array}{l}\text { Correia, Oliveira e Gómez (2016) } \\
\text { Correia-Lima, Costa, Cabral, Silva Filho e Santos (2013) } \\
\text { Duque e Valadão (2017) } \\
\text { Ipiranga, Amorim e Faria (2007) } \\
\text { Mussi, Faraco, Angeloni e Peres (2013) } \\
\text { Vazquez Maguirre, Camacho Ruelas e Garcia Torre (2016) } \\
\text { Webber e Ferreira (2015) }\end{array}$ \\
\hline
\end{tabular}

